\title{
Association between TERT promoter mutations and clinical behaviors in differentiated thyroid carcinoma: a systematic review and meta-analysis
}

\author{
Jing Yang ${ }^{1} \cdot$ Yanping Gong ${ }^{1} \cdot$ Shuping Yan $^{1} \cdot$ Hui Chen $^{2} \cdot$ Siqin Qin $^{3} \cdot$ Rixiang Gong ${ }^{1}$
}

Received: 31 July 2019 / Accepted: 13 October 2019 / Published online: 26 October 2019

(c) The Author(s) 2019

\begin{abstract}
Background The association between telomerase reverse transcriptase (TERT) promoter mutations and some clinical behaviors in thyroid cancer remains controversial and requires additional investigation. This study aimed to evaluate the association between TERT promoter mutations and clinical behaviors (including clinicopathological features and prognosis) in differentiated thyroid carcinomas (DTC).

Methods We performed an up-to-date systematic review and current comprehensive meta-analysis. We searched three electronic databases for relevant studies. We used fixed- or random-effect models to calculate pooled estimated odds ratios (ORs) or standardized mean differences (SMDs) and corresponding 95\% confidence intervals (CIs).

Results We included 51 eligible studies incorporating 11,382 cases. Average frequencies of TERT promoter mutations in DTC, papillary (PTC), and follicular (FTC) thyroid carcinomas were 10.9\%, 10.6\%, and 15.1\%, respectively. In DTC and PTC, TERT promoter mutations were significantly associated with sex, age, tumor size, vascular invasion, extrathyroidal extension, lymph node and distant metastases, advanced tumor, nodes, and metastasis (TNM) stage, persistence/recurrence, and disease-specific mortality. In FTC, TERT promoter mutations were significantly associated with age, distant metastases, advanced TNM stage, persistence/recurrence, and disease-specific mortality.

Conclusions TERT promoter mutations could be considered as biomarkers assisting in risk stratification, prognostic prediction, and individualizing therapeutic options for DTC (PTC and FTC).
\end{abstract}

Keywords $T E R T \cdot \mathrm{DTC} \cdot \mathrm{PTC} \cdot \mathrm{FTC} \cdot$ Clinical behaviors

Supplementary information The online version of this article (https:// doi.org/10.1007/s12020-019-02117-2) contains supplementary material, which is available to authorized users.

Yanping Gong

yanpinggong@Foxmail.com

1 Thyroid and Parathyroid Surgery Center, West China Hospital, Sichuan University, No. 37 Guo Xue Xiang, Chengdu 610041 Sichuan, China

2 West China School of Medicine, Sichuan University, No. 37 Guo Xue Xiang, Chengdu 610041 Sichuan, China

3 Department of General Surgery, the Second People's Hospital of Deyang City, No. 340 West Minjiang Road, Deyang 618000 Sichuan, China

\section{Introduction}

Thyroid cancer is the most common endocrine tumor, and its incidence is increasing worldwide [1]. Among the follicular cell-derived thyroid cancers, papillary (PTC) and follicular (FTC) types are well-differentiated and classified as differentiated thyroid carcinomas (DTC), the most common thyroid malignancy [2]. Although most DTCs have a favorable clinicopathological behavior and improved prognosis, a small proportion of cases show aggressive behavior with adverse outcome [3]. Some clinicopathological factors, such as old age, large tumor size, or distant metastasis, have been associated with poor outcomes of DTC [3, 4]. However, these factors are not entirely reliable in predicting tumor recurrence or cancer-related mortality in DTC. For precise risk stratification, several studies have been conducted to identify some molecular markers in PTC and FTC, such as genetic alterations. 
The telomerase reverse transcriptase (TERT) gene is a $35 \mathrm{~kb}$ gene located on chromosome 5, which contains 16 exons and a promoter region of 330 base pairs (bp) [5]. Mutations in the coding regions of the gene are rare [6]. Interestingly, mutations in the promoter region have been described recently in melanomas through whole-genome sequencing [7, 8], and also quickly found in other human cancers, such as glioma, myxoid liposarcoma, and hepatocellular, urothelial (bladder) [9-11], as well as thyroid [11, 12] carcinomas. Two common recurrent TERT promoter mutations in human cancer are located at two hotspots: chr5, 1,295,228 COT (C228T) and 1,295,250 COT (C250T), corresponding to the positions -124 and $-146 \mathrm{bp}$, respectively, upstream of the ATG start site [7, 8]. Both mutations generate a consensus binding site (GGAA) in the TERT promoter region for E-26 (ETS) transcription factors, which has been shown to confer TERT promoterenhanced transcriptional activities [7, 8, 13].

Since the TERT promoter mutations were reported first by Liu et al. in thyroid cancer [12], subsequently, a large number of studies have reported the association between TERT promoter mutations and clinical behaviors (including pathological features and prognosis) in thyroid cancer, especially in DTC [14-23]. However, some results remain controversial and require additional investigation. Therefore, we performed an up-to-date systematic review and current comprehensive meta-analysis to evaluate the association of TERT promoter mutation and clinical parameters in DTC. These clinical parameters included: mean age, gender, mean tumor size, multifocality, vascular invasion, extrathyroidal extension, lymph node metastasis (LNM), distant metastases, advanced tumor, nodes, and metastasis (TNM) stage, persistence/recurrence, and disease-specific mortality. The meta-analysis results could provide new insight into the biology of TERT promoter mutations and understanding of the clinical significance of these mutation carriers, and offer implications for the design of clinical trials, particularly those of anticancer targeted agents for the $T E R T$ promoter in aggressive thyroid cancers.

\section{Materials and methods}

\section{Selection criteria}

We extensively searched for studies that examined the associations of TERT promoter mutations and clinical parameters in DTC (PTC and/or FTC). In some articles, PTC and FTC were independently analyzed, whereas in other articles, PTC and FTC were synthesized as DTC for analysis. Therefore, DTC (PTC and FTC together) was selected as a separate group for meta-analysis, and PTC and FTC were selected as separate subgroups for meta-analysis.
The inclusion criteria for selecting studies were articles published in English from inception to December 31, 2018, clinical parameters with detailed data on DTC, PTC, and FTC included from articles on different types of thyroid carcinoma (PTC, FTC, medullary, differentiated, poorlydifferentiated, and anaplastic), only studies analyzing at least one category of clinical data, and, when multiple articles were published by the same authors, the newest/ most informative single article was selected. We excluded articles on thyroid cancer subtypes other than DTC, PTC, or FTC; review articles or meta-analyses without original data; single or pure case reports; posters, conference papers, theses, or books; absent or inappropriately reported clinical data; animal or cell lines studies; and duplicated articles. Any disagreements between two reviewers were solved by discussion and consensus.

\section{Search strategy}

We searched PubMed, Embase, and Web of Science databases to identify all potential clinical studies from inception to December 31, 2018. We selected English language articles with a combination of the following search terms: TS $=$ ([TERT OR "telomerase reverse transcriptase"] AND promoter AND thyroid). In addition, we searched for potential studies by reviewing the citations within the included studies and reviews. All procedures strictly followed the recommendation of Preferred Reporting Items for Systematic Review and Meta-analysis statement [24].

\section{Articles screening and data extraction}

Two investigators (Yanping Gong and Jing Yang) used the EndNote (Thompson Reuters, PA, US) reference tool to screen and select articles independently. The full-text of all relevant studies was downloaded consecutively and screened independently by two reviewers. The variables extracted by two investigators independently based on the same rules were first author, publication year, country, number of patients by TERT promoter, number of males or females, mean age at diagnosis, mean tumor size, TNM stages, LNM, extrathyroidal extension, distant metastasis, persistence/recurrence, and disease-specific mortality. We carefully avoided any duplication of data by examining the names of all the authors and the medical centers involved in each publication. Overlapping articles or data and articles unrelated to our questions were excluded. In cases of insufficient or unpublished data, we tried to obtain potential further data by contacting the authors via email. Studies in which clinical parameter data were not provided in the original study or via email were further excluded from the final analyses. 


\section{Quality assessment and risk of bias analysis}

The quality of the included studies was evaluated according to the Newcastle-Ottawa scale (NOS) comprising four stars for selection, two stars for comparability, and three stars for outcome. Two reviewers independently awarded the stars for cohort or case-control studies (maximum nine stars) based on a developed checklist [25]. Studies awarded at least six stars were considered moderate to high-quality and those with a NOS value of less than six were regarded as low-quality.

\section{Data analyses and statistical methods}

STATA 14 software (Stata Corporation, College Station, TX, USA) was used for all statistical analyses, including the calculation of the summary odds ratio (OR) or standardized mean difference (SMD) with a $95 \%$ confidence interval (95\% CI), using a random- or fixed-effect model for all the analyses. The choice of each individual statistical method depended on whether the measured event was dichotomous or continuous, whereas the choice of a random- or fixedeffect model depended on the tests for heterogeneity. We assessed heterogeneity using the $\chi^{2}$ test of heterogeneity and the $I^{2}$ measure of inconsistency. If heterogeneity in the $\chi^{2}$ test or $I^{2}$ measure showed a $P$ value of $<0.10$ or $>50 \%$, respectively, the random-effect model was chosen, otherwise the fixed-effect model was used. The 95\% CI was constructed around the effect size to establish its significance. We conducted a sensitivity analysis to estimate the effects of the remaining studies without the larger one's effect to examine the strength of the outcome. Funnel plot analysis and Egger's test was used to assess the potential for publication bias.
For the OR of dichotomous events, if the $95 \%$ CI of an OR included 1, the two groups were not considered statistically different, otherwise they were considered significant. For continuous event SMD, if the 95\% CI crossed the null point (zero), then the possibility that the difference should be attributed to chance could not be ruled out. When the null point fell outside the $95 \%$ CI of an SMD, the observed difference was considered statistically significant. Funnel plot and/or Egger's regression test was done to assess further the presence of publication bias and calculated by Meta-Essentials: Workbook for meta-analysis [25]. $P<0.05$ was considered statistically significant.

\section{Result}

\section{Search results and quality assessment}

Figure 1 shows the flowchart of the literature research. Initially, 764 studies were included. After removal of duplicates, 443 studies remained. Then, 365 studies were excluded after reviewing the titles and abstracts; 78 full-text studies were evaluated further in detail, and ultimately, 51 studies contributed 11,382 cases with DTC to the metaanalysis for analyzing the correlation between TERT promoter mutation and clinical behaviors in DTC. Of the 51 studies included, 41 and 9 investigated the association between TERT promoter mutation and clinical behaviors in PTC and FTC, respectively. In DTC, the frequencies of TERT promoter mutation ranged from 2.1 to $75 \%$, and overall average frequency was $10.9 \%(1239 / 11,382)$. When calculated in PTC and FTC separately, the average
Fig. 1 Flowchart of section process. TERT, telomerase reverse transcriptase; DTC, differentiated thyroid carcinoma; PTC, papillary thyroid carcinoma; FTC: follicular thyroid carcinoma

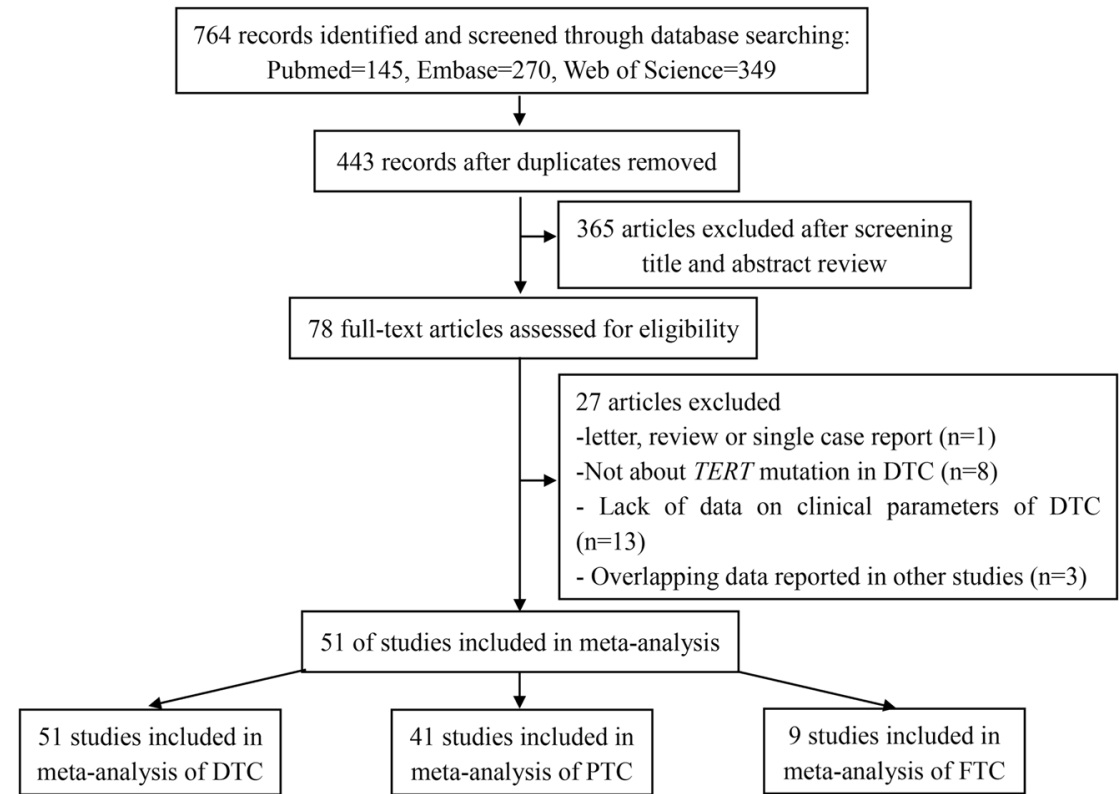


frequencies of TERT promoter mutation were 10.6\% (1027/ 9653 ) and $15.1 \%(79 / 522)$, respectively. The NOS tool was used to assess the quality of the included studies, with five to nine stars awarded to each study. Table 1 describes the characteristics of the included studies and the details of NOS stars given in the meta-analysis.

Among 51 studies of overall DTC, 39 [11, 14-20, 2656], $26[11,14-17,19,20,26-28,32,35,36,38-$ $41,44,45,47,48,51,53,54,56,57], 19$ [11, 14-16, 19, 20, 27, 32, 35, 36, 44, 45, 47, 48, 53, 54, 56-58], $20[17, \quad 19,20,27,30,31,34-37,40,42,46-$ $48,51,54,55,59,60], 11[16,17,20,28,31$, $37,44,50,55,57,60], 29[14-17,19,20,27,30-32,34-$ $37,39,42-46,48-52,54,58,60,61], 39$ [11, 14-20, 27$35, \quad 37-40, \quad 43-46, \quad 48-56, \quad 58-62], 19$ studies $[16,17,20,28,29,31,32,34,38,39,43-47,56$, $60,62,63], 27$ [15-20, 27-32, 34-40, 42-46, 50, 54, 56], $24[16-18,20,27,28,30,31,33,35-38,42,43,46$, $56,58,60,62,64-67]$, and 14 [14, 16, 18, 20, 26, 28, $29,39,42,46,47,60,66,68]$ studies were analyzed for the associations between TERT promoter mutation and gender, mean age, mean tumor size, multifocality, vascular invasion, extrathyroidal extension, LNM, distant metastasis, advanced TNM stage, persistence/recurrence, and diseasespecific mortality, respectively. Among 41 studies of PTC, 32 [11, 14-19, 27-31, 33, 35-40, 42, 43, 45-47, 49-56], 19 $[11,14-17,19,27,28,35,36,38-40,45,47,51$, $53, \quad 54,56], \quad 14 \quad[11, \quad 14-16, \quad 19, \quad 27, \quad 35, \quad 36$, $45,47,53,54,56,58], 16[17,19,27,30,31,35-37$, $40,42,46,47,51,54,55,59], 7$ [16, 17, 28, 31, 37, 50, 55], 23 [14-17, 19, 27, 30, 31, 35-38, 42, 43, 45, 46, 49-52, 54, $58,61], \quad 32[11,14-19,27-31,33,35,37,38$, $40,43,45,46,49-56,58,59,61,62], 15[16,17$, $28,29,31,32,38,39,43,45,46,50,56,62,63], 24$ [15$19,27-31,35-40,42,43,45,46,50,51,54,56], 19$ $[17,18,27,28,30,31,33,35-37,39,42,43$, $46,56,58,62,64,66]$, and $10[14,16,18,28,29,39$, $42,46,66,68]$ studies were analyzed for the abovementioned associations, respectively. Among 9 studies of FTC, 7 [11, 14, 16, 20, 26, 30, 38], 7 [11, 14, 16, 20, 26, $38,57], 4[14,16,20,57], 2[20,30], 3[16,20,57], 3$ [16, 20, 30], 4 [14, 16, 20, 30], 3 [16, 20, 38], 3 [16, 20, 30], $3[20,30,67]$, and $4[14,16,20,26]$ studies were analyzed for the abovementioned associations, respectively.

Fixed-effects models were used for analysis of gender, multifocality, vascular invasion, LNM, persistence/recurrence, and disease-specific mortality in the DTC studies, and in the analysis of gender, multifocality, vascular invasion, LNM, persistence/recurrence, and disease-specific mortality in the PTC studies, whereas random-effects models were chosen for the other analyses. Fixed-effects model was used in the analysis of all the clinical parameters in the FTC studies.
Association between TERT promoter mutations and clinical parameters in DTC

TERT promoter mutations tended to present in older patients (SMD, 1.14; 95\% CI, 0.70-1.59; $P<0.05$ ) and with larger tumor size (SMD, 0.66; 95\% CI, 0.40-0.92; $P<0.05$; Table 2). Besides, TERT promoter mutations were associated with male gender (OR, 1.68; 95\% CI, 1.45-1.95; $P<0.05)$, vascular invasion (OR, 1.81; 95\% CI, 1.35-2.42; $P<0.05)$, extrathyroidal extension (OR, 2.22; 95\% CI, 1.64-3.00; $P<$ 0.05), LNM (OR, 1.53; 95\% CI, 1.31-1.79; $P<0.05)$, distant metastasis (OR, 6.15; 95\% CI, 4.06-9.30; $P<0.05$ ), and advanced TNM stage (OR, 5.68; 95\% CI, 3.93-8.20; $P<0.05)$. TERT promoter mutations were also associated with adverse outcomes, including tumor persistence/recurrence (OR, 5.30; 95\% CI, 4.19-6.71; $P<0.05)$ and diseasespecific mortality (OR, 8.29; 95\% CI, 5.76-11.93; $P<$ $0.05)$. However, TERT promoter mutations were not associated with multifocality (OR, 0.93; 95\% CI, 0.75-1.15; $P=0.478$ ). Forest plots concerning the association of TERT promoter mutation and these clinical parameters are shown in Fig. 2.

\section{Association between TERT promoter mutations and clinical parameters in PTC}

TERT promoter mutation tended to present in older patients (SMD 1.25; 95\% CI, 0.66-1.85; $P<0.05$ ) and with larger tumor size (SMD, 0.60; 95\% CI, 0.27-0.94; $P<0.05$; Table 2). Besides, TERT promoter mutations were associated with male gender (OR, 1.80; 95\% CI, 1.53-2.11; $P<0.05)$, vascular invasion (OR, 1.71; 95\% CI, 1.24-2.35; $P<0.05)$, extrathyroidal extension (OR, $2.3795 \% \mathrm{CI}, 1.71-3.27, P<$ 0.05), LNM (OR, 1.64; 95\% CI, 1.38-1.95; $P<0.05)$, distant metastasis (OR, 6.49; 95\% CI, 3.82-11.01; $P<$ 0.05), and advanced TNM stage (OR, 4.82; 95\% CI, $3.12-7.43 ; P<0.05)$. TERT promoter mutations were also associated with adverse outcomes including tumor persistence/recurrence (OR, 4.97; 95\% CI, 3.78-6.53; $P<0.05)$ and disease-specific mortality (OR, 8.29; 95\% CI, 5.57-12.34; $P<0.05)$. However, TERT promoter mutations were not associated with multifocality (OR, 0.92; 95\% CI, 0.73-1.16; $P=0.890)$. Supplementary Fig. 1 shows forest plots concerning the association of TERT promoter mutation and these clinical parameters.

\section{Association between TERT promoter mutation and clinical behaviors in FTC}

TERT promoter mutation tended to present in older patients (SMD 0.72; 95\% CI, 0.41-1.03; $P<0.05$; Table 2). Besides, TERT promoter mutations were associated with distant metastasis (OR, 24.29; 95\% CI, 6.30-93.58; $P<$ 


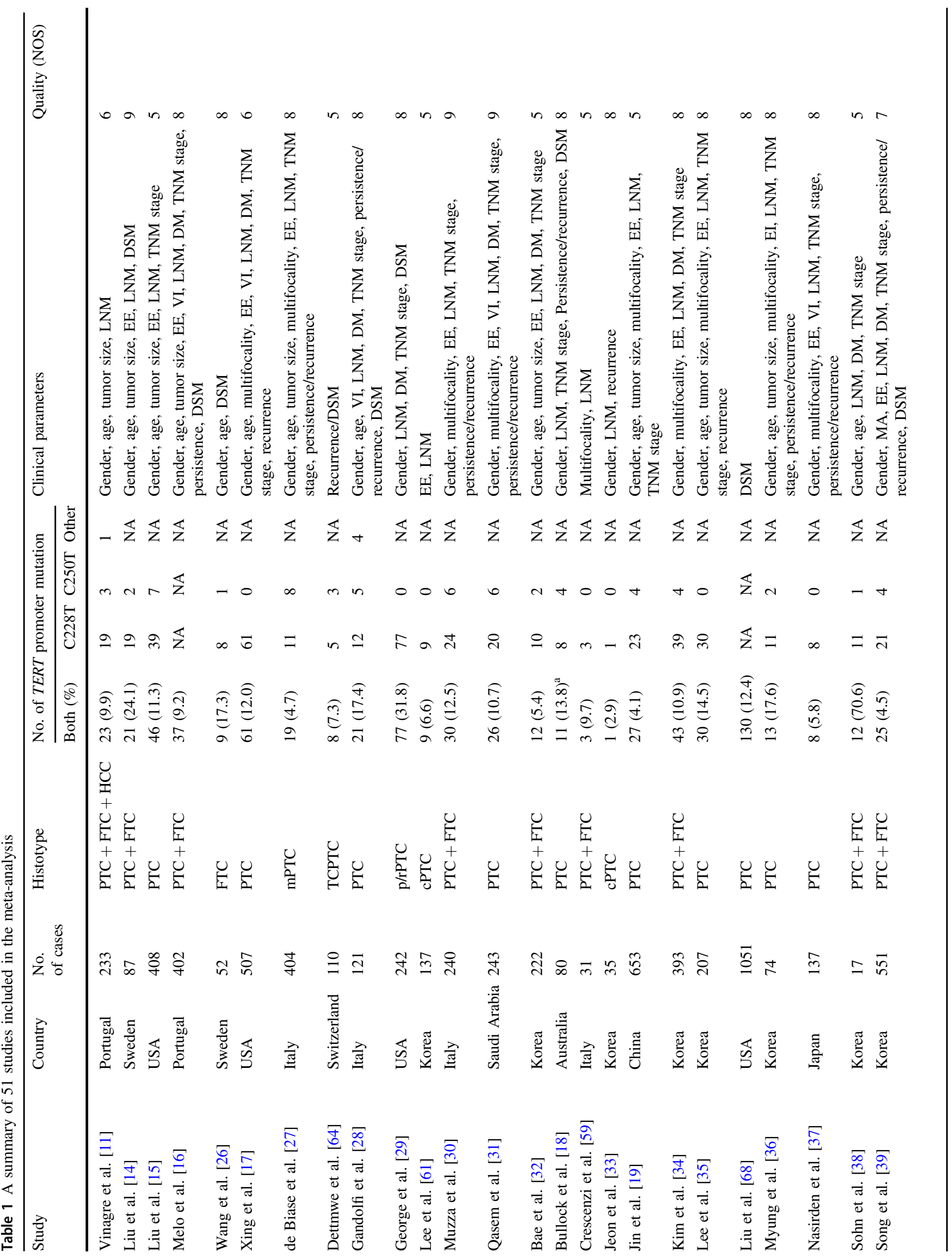




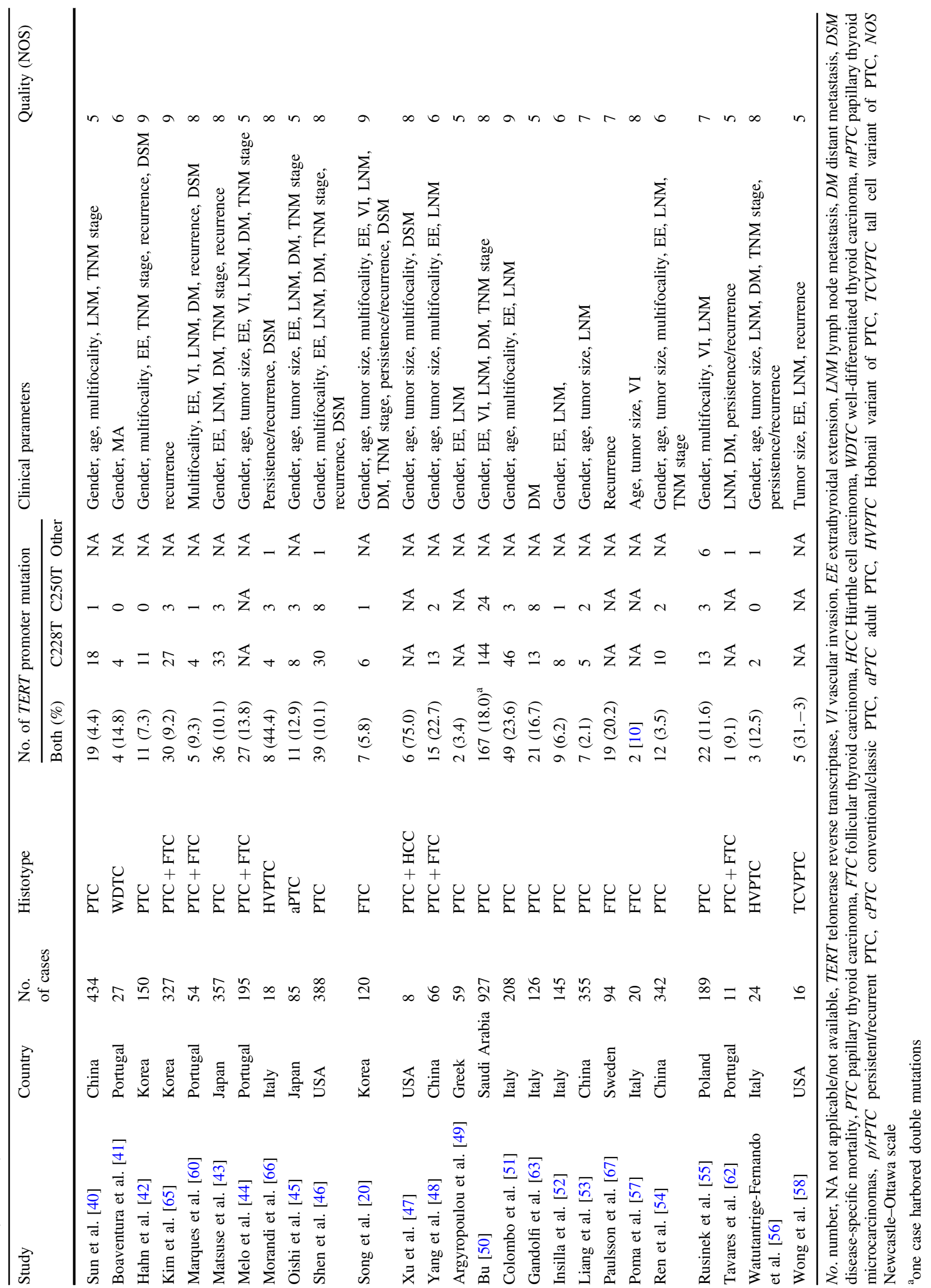


Table 2 Meta-analyses of association between clinical behaviors and TERT promoter mutation in DTC, PTC and FTC

\begin{tabular}{|c|c|c|c|c|c|c|c|c|c|c|c|}
\hline \multirow[t]{2}{*}{ Clinical parameters } & \multirow[t]{2}{*}{$\begin{array}{l}\text { No. of } \\
\text { studies }\end{array}$} & \multirow[t]{2}{*}{$\begin{array}{l}\text { No. } \\
\text { of cases }\end{array}$} & \multicolumn{3}{|c|}{ Heterogeneity test } & \multirow{2}{*}{$\begin{array}{l}\text { Effects } \\
\text { model } \\
\text { selection }\end{array}$} & \multirow[t]{2}{*}{ OR /SMD (95 \% CI) } & \multicolumn{2}{|c|}{$\begin{array}{l}\text { Combined } \\
\text { effect test }\end{array}$} & \multirow[t]{2}{*}{$\begin{array}{l}\text { Statistical } \\
\text { significance }\end{array}$} & \multirow{2}{*}{$\begin{array}{l}\text { Egger's test } \\
P\end{array}$} \\
\hline & & & $\chi^{2}$ & $P$ & $I^{2}$ & & & $Z$ & $P$ & & \\
\hline \multicolumn{12}{|l|}{ DTC } \\
\hline Gender (Male) & 39 & 9226 & 42.33 & 0.289 & $10.2 \%$ & Fixed & $1.68(1.45,1.95)$ & 6.88 & 0.000 & Yes & 0.261 \\
\hline Mean age & 26 & 5732 & 493.94 & 0.000 & $94.9 \%$ & Random & $1.14(0.70,1.59)$ & 5.02 & 0.000 & Yes & 0.195 \\
\hline Mean tumor size & 19 & 3541 & 66.82 & 0.000 & $73.1 \%$ & Random & $0.66(0.40,0.92)$ & 4.96 & 0.000 & Yes & 0.999 \\
\hline Multifocality & 20 & 4745 & 26.53 & 0.116 & $28.4 \%$ & Fixed & $0.93(0.75,1.15)$ & 0.71 & 0.478 & No & 0.151 \\
\hline Vascular invasion & 11 & 2092 & 5.54 & 0.852 & $0.0 \%$ & Fixed & $1.81(1.35,2.42)$ & 3.99 & 0.000 & Yes & 0.688 \\
\hline $\begin{array}{l}\text { Extrathyroidal } \\
\text { extension }\end{array}$ & 29 & 7224 & 63.04 & 0.000 & $55.6 \%$ & Random & $2.22(1.64,3.00)$ & 5.19 & 0.000 & Yes & 0.190 \\
\hline $\begin{array}{l}\text { Lymph node } \\
\text { metastasis }\end{array}$ & 39 & 8374 & 67.42 & 0.002 & $43.6 \%$ & Fixed & $1.53(1.31,1.79)$ & 5.32 & 0.000 & Yes & 0.001 \\
\hline Distant metastasis & 19 & 4608 & 36.51 & 0.006 & $50.7 \%$ & Random & $6.15(4.06,9.30)$ & 8.60 & 0.000 & Yes & 0.079 \\
\hline $\begin{array}{l}\text { Advanced TNM } \\
\text { Stage (III/IV) }\end{array}$ & 27 & 7334 & 82.16 & 0.000 & $68.4 \%$ & Random & $5.68(3.93,8.20)$ & 9.26 & 0.000 & Yes & 0.827 \\
\hline $\begin{array}{l}\text { Persistence/ } \\
\text { recurrence }\end{array}$ & 24 & 4245 & 26.85 & 0.262 & $14.3 \%$ & Fixed & $5.30(4.19,6.71)$ & 13.83 & 0.000 & Yes & 0.105 \\
\hline $\begin{array}{l}\text { Disease-specific } \\
\text { mortality }\end{array}$ & 14 & 3267 & 17.59 & 0.174 & $26.1 \%$ & Fixed & $8.29(5.76,11.93)$ & 11.37 & 0.000 & Yes & 0.146 \\
\hline \multicolumn{12}{|l|}{ PTC } \\
\hline Gender (Male) & 32 & 7824 & 35.36 & 0.270 & $12.3 \%$ & Fixed & $1.80(1.53,2.11)$ & 7.14 & 0.000 & Yes & 0.471 \\
\hline Mean age & 19 & 4742 & 485.60 & 0.000 & $96.3 \%$ & Random & $1.25(0.66,1.85)$ & 4.14 & 0.000 & Yes & 0.162 \\
\hline Mean tumor size & 14 & 2842 & 57.77 & 0.000 & $77.5 \%$ & Random & $0.60(0.27,0.94)$ & 3.51 & 0.000 & Yes & 0.705 \\
\hline Multifocality & 16 & 4052 & 24.20 & 0.062 & $38.0 \%$ & Fixed & $0.92(0.73,1.16)$ & 0.73 & 0.467 & No & 0.151 \\
\hline Vascular invasion & 7 & 1742 & 6.73 & 0.347 & $10.8 \%$ & Fixed & $1.71(1.24,2.35)$ & 3.26 & 0.001 & Yes & 0.171 \\
\hline $\begin{array}{l}\text { Extrathyroidal } \\
\text { extension }\end{array}$ & 23 & 6019 & 48.34 & 0.001 & $54.5 \%$ & Random & $2.37(1.71,3.27)$ & 5.19 & 0.000 & Yes & 0.204 \\
\hline $\begin{array}{l}\text { Lymph node } \\
\text { metastasis }\end{array}$ & 32 & 7105 & 42.25 & 0.086 & $26.6 \%$ & Fixed & $1.64(1.38,1.95)$ & 5.62 & 0.000 & Yes & 0.007 \\
\hline Distant metastasis & 15 & 3684 & 33.59 & 0.002 & $58.3 \%$ & Random & $6.49(3.82,11.01)$ & 6.93 & 0.000 & Yes & 0.103 \\
\hline $\begin{array}{l}\text { Advanced TNM } \\
\text { Stage (III/IV) }\end{array}$ & 24 & 6355 & 93.91 & 0.000 & $75.5 \%$ & Random & $4.82(3.12,7.43)$ & 7.11 & 0.000 & Yes & 0.941 \\
\hline $\begin{array}{l}\text { Persistence/ } \\
\text { recurrence }\end{array}$ & 19 & 3232 & 23.18 & 0.184 & $22.3 \%$ & Fixed & $4.97(3.78,6.53)$ & 11.49 & 0.000 & Yes & 0.118 \\
\hline $\begin{array}{l}\text { Disease-specific } \\
\text { mortality }\end{array}$ & 10 & 2808 & 15.30 & 0.083 & $41.2 \%$ & Fixed & $8.29(5.57,12.34)$ & 10.42 & 0.000 & Yes & 0.128 \\
\hline \multicolumn{12}{|l|}{ FTC } \\
\hline Gender (male) & 7 & 403 & 10.01 & 0.124 & $40.0 \%$ & Fixed & $1.17(0.64,2.15)$ & 0.51 & 0.607 & No & NA \\
\hline Mean age & 7 & 367 & 3.66 & 0.722 & $0.0 \%$ & Fixed & $0.72(0.41,1.03)$ & 4.54 & 0.000 & Yes & NA \\
\hline Mean tumor size & 4 & 235 & 3.05 & 0.384 & $1.6 \%$ & Fixed & $0.14(-0.26,0.54)$ & 0.67 & 0.503 & No & NA \\
\hline Multifocality & 2 & 178 & 0.18 & 0.669 & $0.0 \%$ & Fixed & $0.89(0.19,4.22)$ & 0.15 & 0.880 & No & NA \\
\hline Vascular invasion & 3 & 193 & 0.40 & 0.819 & $0.0 \%$ & Fixed & $2.28(0.75,6.90)$ & 1.46 & 0.144 & No & NA \\
\hline $\begin{array}{l}\text { Extrathyroidal } \\
\text { extension }\end{array}$ & 3 & 227 & 2.70 & 0.260 & $25.9 \%$ & Fixed & $1.57(0.59,4.15)$ & 0.91 & 0.363 & No & NA \\
\hline $\begin{array}{l}\text { Lymph node } \\
\text { metastasis }\end{array}$ & 4 & 261 & 3.32 & 0.345 & $9.6 \%$ & Fixed & $1.96(0.72,5.37)$ & 1.31 & 0.190 & No & NA \\
\hline Distant metastasis & 3 & 159 & 0.99 & 0.611 & $0.0 \%$ & Fixed & $24.29(6.30,93.58)$ & 4.63 & 0.000 & Yes & NA \\
\hline $\begin{array}{l}\text { Advanced TNM } \\
\text { Stage (III/IV) }\end{array}$ & 3 & 207 & 0.45 & 0.798 & $0.0 \%$ & Fixed & $5.10(1.81,14.35)$ & 3.08 & 0.002 & Yes & NA \\
\hline $\begin{array}{l}\text { Persistence/ } \\
\text { recurrence }\end{array}$ & 3 & 272 & 1.67 & 0.425 & $0.0 \%$ & Fixed & $4.59(2.08,10.13)$ & 3.77 & 0.000 & Yes & NA \\
\hline $\begin{array}{l}\text { Disease-specific } \\
\text { mortality }\end{array}$ & 4 & 278 & 0.94 & 0.815 & $0.0 \%$ & Fixed & $9.28(3.35,25.70)$ & 4.28 & 0.000 & Yes & NA \\
\hline
\end{tabular}

No. number, $O R$ odds ratio, SMD standardized mean difference, $C I$ confidence interval, $N A$ not applicable/not available

$0.05)$ and advanced TNM stage (OR, 5.10; 95\% CI, $1.81-14.35 ; P<0.05)$. TERT promoter mutations were also associated with adverse outcomes including tumor persistence/recurrence (OR, 4.59; 95\% CI, 2.08-10.13 $P<0.05$ ) and disease-specific mortality (OR, 9.28; 95\% CI, $3.35-25.70 ; P<0.05)$. However, TERT promoter mutations were not associated with gender (OR, $1.17 ; 95 \% \mathrm{CI}$, $0.64-2.15 ; P=0.607$ ), tumor size (SMD, $0.14 ; 95 \% \mathrm{CI}$, 

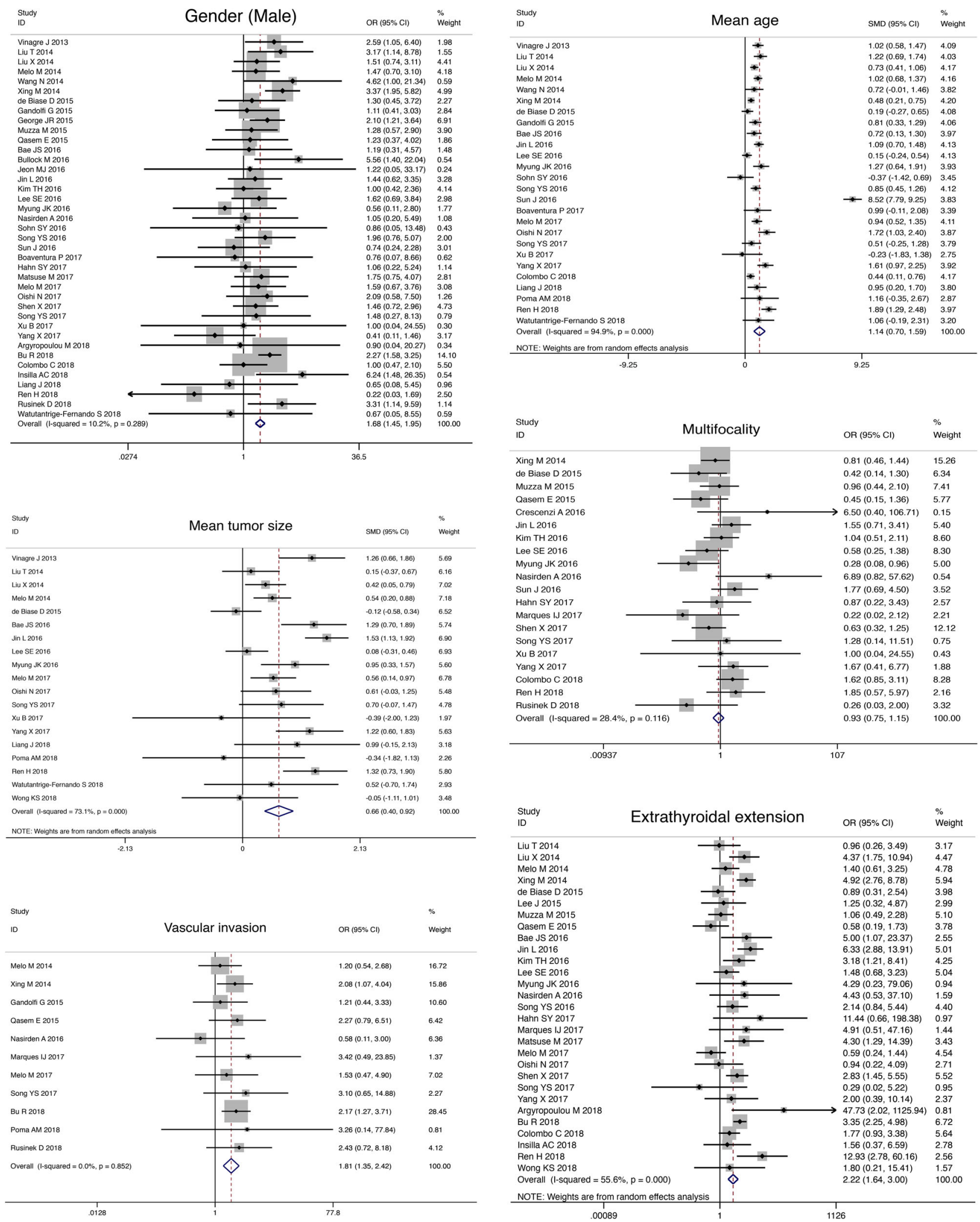

Fig. 2 Forest plot showing the association of TERT promoter mutations with clinical parameters in DTC 

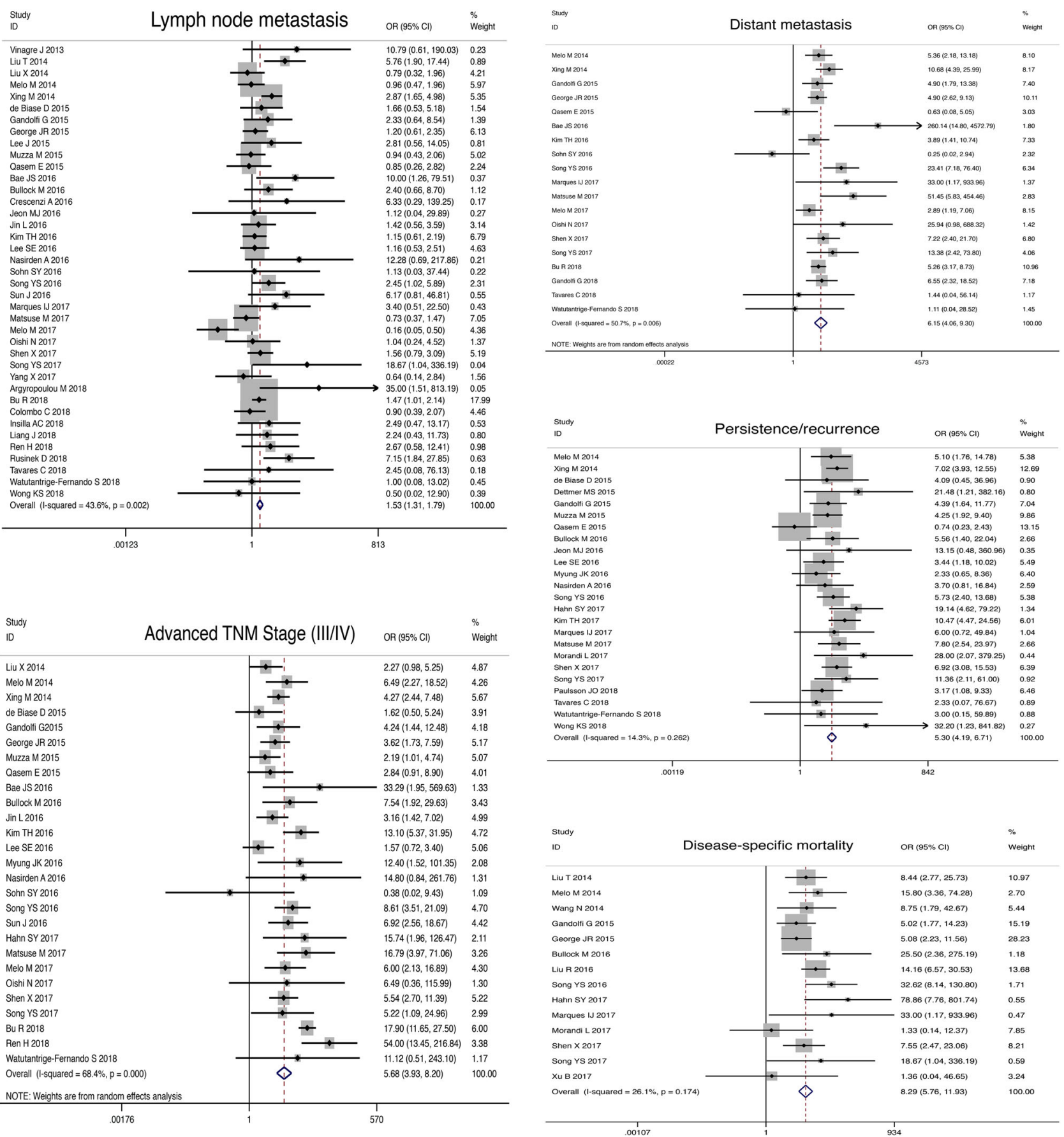

Fig. 2 Continued

-0.26 to $0.54 ; P=0.503$ ), multifocality (OR, $0.89 ; 95 \%$ CI, 0.19-4.22; $P=0.880$ ), vascular invasion (OR, 2.28; 95\% CI, 0.75-6.90; $P=0.144)$, extrathyroidal extension (OR, 1.57; 95\% CI, 0.59-4.15, $P=0.363$ ), and LNM (OR, 1.96; 95\% CI, 0.72-5.37; $P=0.190)$. Supplementary Fig. 2 shows forest plots concerning the association of TERT promoter mutation and these clinical parameters.

\section{Heterogeneity assessment}

We used sensitivity analysis by removing each of the included studies to find which studies influenced the degree of heterogeneity. All the significant pooled results following the leave-one-out method remained unaffected. 


\section{Publication bias}

Funnel plot observation did not show strong evidence of publication bias among the set of studies. Except for the analysis of LNM in DTC and PTC, most of Egger's regression test of all the effects did not suggest any evidence of publication bias (data shown in Table 2). When we simultaneously eliminated four studies by Vinagre et al. [11], Nasirden et al. [37], Song et al. [48], and Argyropoulu et al. [49] on DTC and eliminated four studies by Vinagre et al. [11], Liu et al. [14], Nasirden et al. [37], and Argyropoulu et al. [49] on PTC for analysis of LNM, these publication biases disappeared and the significant pooled results remained unaffected. In FTC, Egger's regression test was not performed because of the small numbers of included studies.

\section{Discussion}

Many somatic genetic alterations, including those in BRAF, HRAS, KRAS, NRAS, PTEN, and HERl, have had fundamental roles in the tumorigenesis of thyroid carcinoma. Recently, the close association of TERT promoter somatic mutations with tumorigenesis is widely recognized also. Since Liu et al. first directly investigated the diagnostic and prognostic potentials of preoperative testing of thyroid fine-needle aspiration biopsy (FNAB) specimens for the TERT promoter mutations in thyroid cancer [12], a significant interest in TERT promoter mutations (mainly C228T and C250T) focused on the frequency of these mutations in different subtypes of thyroid cancer and their association with clinicopathological features and outcomes of thyroid cancer has accumulated. A large number of publications have been generated over the last $\sim 5$ years. It is not controversial that the TERT promoter mutations are associated with poor outcome. However, the associations between TERT promoter mutations and some clinicopathological features remain discrepant. Our study aimed to explore the influence of TERT promoter somatic mutations on the clinicopathological features and prognosis of DTC via an updated meta-analysis. In our study, the results of meta-analyses of PTC were in line with those of DTC, but some results of FTC not with those of DTC. This may be attributed to the fact that the sample capacity of DTC has derived mainly from PTC cases, but lesser from FTC cases. To the best of our knowledge, our study is the up-to-date meta-analysis evaluating the association between TERT promoter mutation and clinical behaviors in PTC, and it is the first meta-analysis independently investigating the association between TERT promoter mutations and clinical behaviors in FTC.
Although two similar meta-analyses had been performed to investigate the association of TERT promoter mutations with clinicopathological features and prognosis of PTC, their literature searches were performed in November 2015 and the numbers of included studies were small (eight and ten studies respectively) [21, 22]. However, our literatures searches were performed from the inception to December 31,2018 , and 51 studies were included in our study, 41 of which investigated the association between TERT promoter mutation and clinical behaviors in PTC. Besides, our study included the overall clinicopathological and prognostic parameters. In the present study, the overall average frequency of TERT promoter mutations was $10.9 \%$ in DTC, which was close to that in PTC $(10.6 \%)$. This is because the number of PTC cases was greater than that of FTC (9653:522). In some publications, the frequency of TERT promoter mutations was reported to be as high as $75 \%$ and as low as $2.1 \%$. This can possibly be attributed to small sample size. In the previous two studies, the average frequencies of TERT promoter mutation in PTC were 10.3\% and $10.1 \%$, respectively [21, 22]. In our study, the average frequency in PTC was $10.6 \%$, which was similar to the previously reported results [21, 22]. Almost all previous studies reported no collective prevalence of TERT promoter mutations in normal thyroid parenchyma or benign thyroid lesions [11, 12, 15, 16, 30, 69], such as nodular goiter (hyperplasia lesions), diffuse toxic goiters, lymphocytic (Hashimoto's) thyroiditis, and follicular thyroid adenomas (FTA). The TERT promoter mutations were sporadically reported only in two FTAs [26, 70]. Therefore, we postulated that TERT promoter mutation may have an important role in preoperative diagnosis of thyroid carcinoma, especially for patients with indeterminate cytology on FNAB.

Some aggressive clinicopathological characters, for example, male gender, larger tumor size, extrathyroidal extension, LNM, distant metastasis, and advanced TNM stage, were correlated with poor prognostic features, such as persistence/recurrence and disease-specific mortality in previous studies [18, 23]. Previous meta-analyses suggested that TERT promoter mutations were associated with these aggressive clinicopathological characteristics [21, 22], which were mainly in accordance with the results of our meta-analysis. Our findings indicated that TERT promoter mutations were more likely to be present in male patients, and those of older age, with larger tumor size, and stronglyassociated vascular invasion, extrathyroidal extension, LNM, distant metastasis, and advanced TNM stage in PTC. However, the previous two meta-analyses found that the association of TERT promoter mutations with vascular invasion was not significant $(P=0.20$ and 0.11 , respectively), and extrathyroidal extension was at a critical level in terms of an association with TERT promoter mutations ( $P=0.03$ and 0.06 , respectively) $[21,22]$. This finding may 
be explained by the fact that these studies, including the data on focus numbers of vascular invasion and extrathyroidal extension, were relatively small. Consistently, one finding in the studies by Yin et al. [21] and Liu et al. [22] and our study was that TERT promoter mutations were not associated with multifocality. To the best of our knowledge, there were no studies showing that TERT promoter mutations were associated with multifocality. The previous metaanalyses studies and our meta-analysis conformably demonstrated that patients with TERT promoter mutations in PTC were more likely to experience persistence or recurrence, and TERT promoter mutations more likely gave rise to mortality for patients with PTC. Therefore, we concluded that TERT promoter mutations are responsible for more aggressive clinicopathological features and may represent a poor prognostic factor in PTC. However, the poor prognosis in patients with PTC may be affected also by treatment factors, such as type of surgery, iodine-131 $\left(\mathrm{I}^{131}\right)$ ablation, and the use of external radiotherapy. Therefore, different approaches may be used for their clinical management. More invasive treatment strategies, such as total thyroidectomy or central lymph node dissection, may be considered in patients with PTC presenting TERT promoter mutations to decrease recurrence or mortality.

In FTC, the average frequency of TERT promoter mutations was $15.1 \%$, which was higher than that in PTC. The majority of the studies reported TERT promoter mutations were not detected in FTA $[16,67,69,71]$. However, a current case report study showed TERT promoter (C228T) mutation in a patient with FTA [70]. In addition, another study reported positive TERT promoter (C228T) mutations in four (5.3\%) of 76 adenomas included in that study, but three of them were atypical follicular thyroid adenomas (AFTA) [26], which are now classified as follicular tumor of uncertain malignant potential by the World Health Organisation (WHO) 2017 guidelines [72]. The single case with TERT promoter-mutated FTA later developed scar recurrence and died of FTC [26]. Thus, they concluded that TERT promoter mutations may occur as an early genetic event in thyroid follicular tumors that have not developed malignant features on routine histopathological workup. However, this unexpected finding of TERT promoter mutations in FTA has rarely been reported, and further studies with larger sample sizes are needed to detect the gene mutation and explain the mechanism. Therefore, this conclusion should be interpreted cautiously.

Furthermore, our study showed that there was no association between TERT promoter mutations and most aggressive clinicopathological characteristics in FTC, such as larger tumor size, male gender, vascular invasion, extrathyroidal extension, and LNM, which differed from the results of PTC. This difference might be related to the relatively small sample of FTC. The current study suggested that TERT promoter mutations more likely tended to present in older patients with FTC, and were only associated with distant metastasis and advanced TNM stage, but not with gender, tumor size, multifocality, vascular invasion, extrathyroidal extension, and LNM. With the exception of the study by Song et al. [20], which showed that TERT promoter mutations were not associated with age, the other results of association between TERT promoter mutations and clinicopathological characteristics of FTC were consistent with those of the studies by Wang et al. [26], Muzza et al. [30], and Song et al. [20]. Therefore, there are differences between PTC and FTC in the contributions of TERT promoter mutations to clinicopathological features. However, it is coincident that there are strongly association between TERT promoter mutations and distant metastasis $(\mathrm{OR}=6.15,6.49$, and 24.29 , respectively) and advanced TNM stage $(\mathrm{OR}=5.68,4.82$, and 5.10 , respectively $)$ in DTC, PTC, and FTC. Compared with other clinicopathological features, the TERT promoter mutations possibly make more contribution to distant metastasis and advanced TNM stage of DTC, especially to distant metastasis of FTC $(\mathrm{OR}=24.29)$. As described in nearly all the relevant literature on prognosis [16, 20, 26, 67], our metaanalysis showed that TERT promoter mutations were strongly associated with persistence/recurrence, and disease-specific mortality, and indicated that patients with TERT promoter mutations in FTC also have poor prognosis. Thus, TERT promoter mutations may be considered biomarkers for prognosis in FTC. However, more valuable studies on a large cohort of cases are required to evaluate the clinical behavior in patients with FTC.

There were some limitations in this meta-analysis. First, most studies were designed retrospectively, which may cause potential selection bias to better-documented patients and larger tumors, since they were more available for collection and analysis. Second, heterogeneity was present in some analyses probably due to confounding factors, such as patient demographics, ethnicity, sample source, therapeutic approaches, duration of follow-up, and so forth. Furthermore, most of the aggressive variables are interrelated. For example, patients with more advanced disease tend to have LNM and, thus, disease stage may confound the association between TERT promoter mutations and LNM. Lastly, the sample sizes of some included articles are relatively small (especially in FTC), and relevant unpublished data could not be obtained for further analysis. Therefore, our conclusions should be interpreted cautiously.

\section{Conclusion}

In conclusion, this meta-analysis demonstrated that TERT promoter mutations were likely to present in older patients 
and were strongly associated with distant metastasis, advanced tumor stage, disease persistence/recurrence, and disease-specific mortality in DTC, and also were associated with male gender, larger tumor size, vascular invasion, extrathyroidal extension, and LNM in PTC, but not in FTC. Therefore, DTC with TERT promoter mutations present aggressively clinical behaviors, and TERT promoter mutations could be considered as biomarkers assisting in risk stratification, prognostic prediction, and individualizing therapeutic options for DTC (PTC and FTC). However, more and further studies are needed to evaluate the role of TERT promoter mutations in FTC.

Funding This work was supported by grants from Department of Sichuan Province, Science and Technology Support Program (Grant Agreement No. 2018SZ0215). Sources of funding for research and/or publication: Department of Sichuan Province, Science and Technology Support Program (Grant Agreement No. 2018SZ0215).

\section{Compliance with ethical standards}

Conflict of interest The authors declare that they have no conflict of interest.

Publisher's note Springer Nature remains neutral with regard to jurisdictional claims in published maps and institutional affiliations.

Open Access This article is distributed under the terms of the Creative Commons Attribution 4.0 International License (http://crea tivecommons.org/licenses/by/4.0/), which permits unrestricted use, distribution, and reproduction in any medium, provided you give appropriate credit to the original author(s) and the source, provide a link to the Creative Commons license, and indicate if changes were made.

\section{References}

1. N. Howlader, A.M. Noone, M. Krapcho, D. Miller, K. Bishop, C. L. Kosary, M. Yu, J. Ruhl, Z. Tatalovich, A., Mariotto, D.R. Lewis, H.S. Chen, E.J. Feuer, K.A. Cronin (eds), SEER Cancer Statistics Review, 1975-2014, National Cancer Institute. Bethesda, MD, https://seer.cancer.gov/csr/1975_2014/, based on November 2016 SEER data submission, posted to the SEER web site, April 2017

2. M. Xing, Molecular pathogenesis and mechanisms of thyroid cancer. Nat. Rev. Cancer 13, 184-199 (2013)

3. R.K. Orosco, T. Hussain, K.T. Brumund, D.K. Oh, D.C. Chang, M. Bouvet, Analysis of age and disease status as predictors of thyroid cancer-specific mortality using the surveillance, epidemiology, and end results database. Thyroid 25, 125-132 (2015)

4. B.R. Haugen, E.K. Alexander, K.C. Bible, G.M. Doherty, S.J. Mandel, Y.E. Nikiforov, F. Pacini, G.W. Randolph, A.M. Sawka, M. Schlumberger, K.G. Schuff, S.I. Sherman, J.A. Sosa, D.L. Steward, R.M. Tuttle, L. Wartofsky, 2015 American thyroid association management guidelines for adult patients with thyroid nodules and differentiated thyroid cancer: the American thyroid association guidelines task force on thyroid nodules and differentiated thyroid cancer. Thyroid 26, 1-133 (2016)

5. Y.S. Cong, J. Wen, S. Bacchetti, The human telomerase catalytic subunit hTERT: organization of the gene and characterization of the promoter. Hum. Mol. Genet. 8, 137-142 (1999)
6. G. Aubert, P.M. Lansdorp, Telomeres and aging. Physiol. Rev. 88, 557-579 (2008)

7. S. Horn, A. Figl, P.S. Rachakonda, C. Fischer, A. Sucker, A. Gast, S. Kadel, I. Moll, E. Nagore, K. Hemminki, D. Schadendorf, R. Kumar, TERT promoter mutations in familial and sporadic melanoma. Science 339, 959-961 (2013)

8. F.W. Huang, E. Hodis, M.J. Xu, G.V. Kryukov, L. Chin, L.A. Garraway, Highly recurrent TERT promoter mutations in human melanoma. Science 339, 957-959 (2013)

9. P.J. Killela, Z.J. Reitman, Y. Jiao, C. Bettegowda, N. Agrawal, L. A.L.A. Diaz Jr, A.H. Friedman, H. Friedman, G.L. Gallia, B.C. Giovanella, A.P. Grollman, T.C. He, Y. He, R.H. Hruban, G.L. Jallo, N. Mandahl, A.K. Meeker, F. Mertens, G.J. Netto, B.A. Rasheed, G.J. Riggins, T.A. Rosenquist, M. Schiffman, Ie.M. Shih, D. Theodorescu, M.S. Torbenson, V.E. Velculescu, T.L. Wang, N. Wentzensen, L.D. Wood, M. Zhang, R.E. McLendon, D.D. Bigner, K.W. Kinzler, B. Vogelstein, N. Papadopoulos, H. Yan, TERT promoter mutations occur frequently in gliomas and a subset of tumors derived from cells with low rates of self-renewal. PNAS 110, 6021-6026 (2013)

10. X. Liu, G. Wu, Y. Shan, Highly prevalent TERT promoter mutations in bladder cancer and glioblastoma. Cell Cycle 12, 1637-1638 (2013)

11. J. Vinagre, A. Almeida, H. Pópulo, R. Batista, J. Lyra, V. Pinto, R. Coelho, R. Celestino, H. Prazeres, L. Lima, M. Melo, A.G. da Rocha, A. Preto, P. Castro, L. Castro, F. Pardal, J.M. Lopes, L.L. Santos, R.M. Reis, J. Cameselle-Teijeiro, M. Sobrinho-Simões, J. Lima, V. Máximo, P. Soares, Frequency of TERT promoter mutations in human cancers. Nat. Commun. 4, 2185 (2013)

12. X. Liu, J. Bishop, Y. Shan, S. Pai, D. Liu, A.K. Murugan, H. Sun, A.K. El-Naggar, M. Xing, Highly prevalent TERT promoter mutations in aggressive thyroid cancers. Endocr.-Relat. Cancer 20, 603-610 (2013)

13. R.J. Bell, H.T. Rube, A. Kreig, A. Mancini, S.D. Fouse, R.P. Nagarajan, S. Choi, C. Hong, D. He, M. Pekmezci, J.K. Wiencke, M.R. Wrensch, S.M. Chang, K.M. Walsh, S. Myong, J.S. Song, J. F. Costello, The transcription factor GABP selectively binds and activates the mutant TERT promoter in cancer. Science 348, 1036-1039 (2015)

14. T. Liu, N. Wang, J. Cao, The age- and shorter telomere-dependent TERT promoter mutation in follicular thyroid cell-derived carcinomas. Oncogene 33, 4978-4984 (2014)

15. X. Liu, S. Qu, R. Liu, C. Sheng, X. Shi, G. Zhu, A.K. Murugan, H. Guan, H. Yu, Y. Wang, H. Sun, Z. Shan, W. Teng, M. Xing, M. TERT, promoter mutations and their association with $B R A F$ V600E mutation and aggressive clinicopathological characteristics of thyroid cancer. J. Clin. Endocrinol. Metab. 99, E1130-E1136 (2014)

16. M. Melo, A.G. da Rocha, J. Vinagre, R. Batista, J. Peixoto, C. Tavares, R. Celestino, A. Almeida, C. Salgado, C. Eloy, P. Castro, H. Prazeres, J. Lima, T. Amaro, C. Lobo, M.J. Martins, M. Moura, B. Cavaco, V. Leite, J.M. Cameselle-Teijeiro, F. Carrilho, M. Carvalheiro, V. Máximo, M. Sobrinho-Simões, P. Soares, TERT promoter mutations are a major indicator of poor outcome in differentiated thyroid carcinomas. J. Clin. Endocrinol. Metab. 99, E754-E765 (2014)

17. M. Xing, R. Liu, X. Liu, A.K. Murugan, G. Zhu, M.A. Zeiger, S. Pai, J. Bishop, BRAF V600E and TERT promoter mutations cooperatively identify the most aggressive papillary thyroid cancer with highest recurrence. J. Clin. Oncol. 32, 2718-2726 (2014)

18. M. Bullock, Y. Ren, C. O'Neill, A. Gill, A. Aniss, M. Sywak, S. Sidhu, L. Delbridge, D. Learoyd, F. de Vathaire, B.G. Robinson, R.J. Clifton-Bligh, TERT promoter mutations are a major indicator of recurrence and death due to papillary thyroid carcinomas. Clin. Endocrinol. 85, 283-290 (2016) 
19. L. Jin, E. Chen, S. Dong, Y. Cai, X. Zhang, Y. Zhou, R. Zeng, F. Yang, C. Pan, Y. Liu, W. Wu, M. Xing, X. Zhang, O. Wang, $B R A F$ and TERT promoter mutations in the aggressiveness of papillary thyroid carcinoma: A study of 653 patients. Oncotarget 7, 18346-18355 (2016)

20. Y.S. Song, J.A. Lim, H.S. Min, M.J. Kim, H.S. Choi, S.W. Cho, J. H. Moon, K.H. Yi, D.J. Park, B.Y. Cho, Y.J. Park, Changes in the clinicopathological characteristics and genetic alterations of follicular thyroid cancer. Eur. J. Endocrinol. 177, 465-473 (2017)

21. D.T. Yin, K. Yu, R.Q. Lu, X. Li, J. Xu, M. Lei, H. Li, Y. Wang, Z. Liu, Clinicopathological significance of TERT promoter mutation in papillary thyroid carcinomas: a systematic review and meta-analysis. Clin. Endocrinol. 85, 299-305 (2016)

22. C. Liu, Z. Liu, T. Chen, W. Zeng, Y. Guo, T. Huang, TERT promoter mutation and its association with clinicopathological features and prognosis of papillary thyroid cancer: a metaanalysis. Sci. Rep. 6, 36990 (2016)

23. S.J. Kim, S.Y. Park, Y.J. Lee, E.K. Lee, S.K. Kim, T.H. Kim, Y.S. Jung, J. Ryu, J.P. Myong, K.W. Chung, Risk factors for recurrence after therapeutic lateral neck dissection for primary papillary thyroid cancer. Ann. Surg. Oncol. 21, 1884-1890 (2014)

24. D. Moher, A. Liberati, J. Tetzlaff, D.G. Altman; PRISMA Group, Preferred reporting items for systematic reviews and meta-analyses: the PRISMA statement. PLoS Med. 6, e100097 (2009)

25. G.A. Wells, B. Shea, D. O'Connell, The Newcastle-Ottawa Scale (NOS) for assessing the quality of nonrandomised studies in metaanalyses. (Ottawa: Ottawa Hospital Institute, 2018). http://www. ohri.ca/programs/clinical_epidemiology/oxford.asp. Accessed 10 Feb 2018

26. N. Wang, T. Liu, A. Sofiadis, C.C. Juhlin, J. Zedenius, A. Höög, C. Larsson, D. Xu, TERT promoter mutation as an early genetic event activating telomerase in follicular thyroid adenoma (FTA) and atypical FTA. Cancer 120, 2965-2979 (2014)

27. D. de Biase, G. Gandolfi, M. Ragazzi, M. Eszlinger, V. Sancisi, M. Gugnoni, M. Visani, A. Paession, G. Casadei, C. Durante, G. Costante, R. Bruno, M. Torlontano, R. Paschke, S. Filetti, S. Piana, A. Frasoldati, G. Tallini, A. Ciarrocchi, TERT promoter mutations in papillary thyroid microcarcinomas. Thyroid $\mathbf{2 5}$, 1013-1019 (2015)

28. G. Gandolfi, M. Ragazzi, A. Frasoldati, S. Piana, A. Ciarrocchi, V. Sancisi, TERT promoter mutations are associated with distant metastases in papillary thyroid carcinoma. Eur. J. Endocrinol. 172, 403-413 (2015)

29. J.R. George, Y.C. Henderson, M.D. Williams, D.B. Roberts, H. Hei, S.Y. Lai, G.L. Clayman, Association of TERT promoter mutation, but not BRAF mutation, with increased mortality in PTC. J. Clin. Endocrinol. Metab. 100, E1550-E1559 (2015)

30. M. Muzza, C. Colombo, S. Rossi, D. Tosi, V. Cirello, M. Perrino, S. De Leo, E. Magnani, E. Pignatti, B. Vigo, M. Simoni, G. Bulfamante, L. Vicentini, L. Fugazzola, Telomerase in differentiated thyroid cancer: promoter mutations, expression and localization. Mol. Cell Endocrinol. 399, 288-295 (2015)

31. E. Qasem, A.K. Murugan, H. Al-Hindi, M. Xing, M. Almohanna, M. Alswailem, A.S. Alzahrani, TERT promoter mutations in thyroid cancer: a report from a Middle Eastern population. Endocr. Relat. Cancer 22, 901-908 (2015)

32. J.S. Bae, Y. Kim, S. Jeon, S.H. Kim, T.J. Kim, S. Lee, M.H. Kim, D.J. Lim, Y.S. Lee, C.K. Jung, Clinical utility of TERT promoter mutations and $A L K$ rearrangement in thyroid cancer patients with a high prevalence of the BRAF V600E mutation. Diagn. Pathol. 11, 21 (2016)

33. M.J. Jeon, W.G. Kim, S. Sim, S. Lim, H. Kwon, T.Y. Kim, Y.K. Shong, W.B. Kim, Low prevalence of somatic TERT promoter mutations in classic papillary thyroid carcinoma. Endocrinol. Metab. 31, 100-104 (2016)
34. T.H. Kim, Y.E. Kim, S. Ahn, J.Y. Kim, C.S. Ki, Y.L. Oh, K. Kim, J.W. Yun, W.Y. Park, J.H. Choe, J.H. Kim, J.S. Kim, S.W. Kim, J.H. Chung, TERT promoter mutations and long-term survival in patients with thyroid cancer. Endocr. Relat. Cancer 23, 813-823 (2016)

35. S.E. Lee, T.S. Hwang, Y.L. Choi, H.S. Han, W.S. Kim, M.H. Jang, S.K. Kim, J.H. Yang, Prognostic significance of TERT promoter mutations in papillary thyroid carcinomas in a BRAF (V600E) mutation-prevalent population. Thyroid 26, 901-910 (2016)

36. J.K. Myung, B.K. Kwak, J.A. Lim, M.C. Lee, M.J. Kim, TERT promoter mutations and tumor persistence/recurrence in papillary thyroid cancer. Cancer Res. Treat. 48, 942-947 (2016)

37. A. Nasirden, T. Saito, Y. Fukumura, K. Hara, K. Akaike, A. Kurisaki-Arakawa, M. Asahina, A. Yamashita, R. Tomomasa, T. Hayashi, A. Arakawa, T. Yao, In Japanese patients with papillary thyroid carcinoma, TERT promoter mutation is associated with poor prognosis, in contrast to BRAF V600E mutation. Virchows Arch. 469, 687-696 (2016)

38. S.Y. Sohn, W.Y. Park, H.T. Shin, J.S. Bae, C.S. Ki, Y.L. Oh, S. W. Kim, J.H. Chung, Highly concordant key genetic alterations in primary tumors and matched distant metastases in differentiated thyroid cancer. Thyroid 26, 672-682 (2016)

39. Y.S. Song, J.A. Lim, H. Choi, J.K. Won, J.H. Moon, S.W. Cho, K.E. Lee, Y.J. Park, K.H. Yi, Dj Park, J.S. Seo, Prognostic effects of TERT promoter mutations are enhanced by coexistence with $B R A F$ or $R A S$ mutations and strengthen the risk prediction by the ATA or TNM staging system in differentiated thyroid cancer patients. Cancer 122, 1370-1379 (2016)

40. J. Sun, J. Zhang, J. Lu, J. Gao, X. Ren, L. Teng, H. Duan, Y. Lin, X. Li, B. Zhang, Z. Liang, BRAF V600E and TERT promoter mutations in papillary thyroid carcinoma in Chinese patients. PLoS ONE 11, e0153319 (2016)

41. P. Boaventura, R. Batista, A. Pestana, M. Reis, A. Mendes, C. Eloy, M. Sobrinho-Simões, P. Soares, TERT promoter mutations: a genetic signature of benign and malignant thyroid tumours occurring in the context of tinea capitis irradiation. Eur. J. Endocrinol. 176, 49-55 (2017)

42. S.Y. Hahn, T.H. Kim, C.S. Ki, S.W. Kim, S. Ahn, J.H. Shin, J.H Chung, Ultrasound and clinicopathological features of papillary thyroid carcinomas with BRAF and TERT promoter mutations. Oncotarget 8, 108946-108957 (2017)

43. M. Matsuse, T. Yabuta, V. Saenko, M. Hirokawa, E. Nishihara, K. Suzuki, S. Yamashita, A. Miyauchi, N. Mitsutake, TERT promoter mutations and Ki-67 labeling index as a prognostic marker of papillary thyroid carcinomas: combination of two independent factors. Sci. Rep. 7, 41752 (2017)

44. M. Melo, A. Gaspar da Rocha, R. Batista, J. Vinagre, M.J. Martins, G. Costa, C. Ribeiro, F. Carrilho, V. Leite, C. Lobo, J.M. Cameselle-Teijeiro, B. Cavadas, L. Pereira, M. Sobrinho-Simões, P. Soares, TERT, BRAF, and NRAS in primary thyroid cancer and metastatic disease. J. Clin. Endocrinol. Metab. 102, 1898-1907 (2017)

45. N. Oishi, T. Kondo, T. Nakazawa, K. Mochizuki, T. Inoue, K. Kasai, I. Tahara, T. Yabuta, M. Hirokawa, A. Miyauchi, R. Katoh, Frequent BRAF V600E and absence of TERT promoter mutations characterize sporadic pediatric papillary thyroid carcinomas in Japan. Endocr. Pathol. 28, 103-111 (2017)

46. X. Shen, R. Liu, M. Xing, A six-genotype genetic prognostic model for papillary thyroid cancer. Endocr. Relat. Cancer 24, 41-52 (2017)

47. B. Xu, R.M. Tuttle, M.M. Sabra, I. Ganly, R. Ghossein, Primary thyroid carcinoma with low-risk histology and distant metastases: clinicopathologic and molecular characteristics. Thyroid 27, 632-640 (2017) 
48. X. Yang, J. Li, X. Li, Z. Liang, W. Gao, J. Liang, S. Cheng, Y. Lin, TERT promoter mutation predicts radioiodine-refractory character in distant metastatic differentiated thyroid cancer. J. Nucl. Med. 58, 258-265 (2017)

49. M. Argyropoulou, A.S. Veskoukis, P.M. Karanatsiou, A. Manolakelli, I. Kostoglou-Athanassiou, G. Vilaras, A. Karameris, K. Liadaki, Low prevalence of TERT promoter, BRAF and RAS mutations in papillary thyroid cancer in the Greek population. Pathol. Oncol. Res. (2018) https://doi.org/10.1007/s12253-0180497-2. [Epub ahead of print]

50. R. Bu, A.K. Siraj, S.P. Divya, Y. Kong, S.K. Parvathareddy, M. Al-Rasheed, K.A.S. Al-Obaisi, I.G. Victoria, S.S. Al-Sobhi, M. Al-Dawish, F. Al-Dayel, K.S. Al-Kuraya, Telomerase reverse transcriptase mutations are independent predictor of disease-free survival in Middle Eastern papillary thyroid cancer. Int J. Cancer 142, 2028-2039 (2018)

51. C. Colombo, M. Muzza, M.C. Proverbio, D. Tosi, D. Soranna, C. Pesenti, S. Rossi, V. Cirello, S. De Leo, N. Fusco, M. Miozzo, G. Bulfamante, L. Vicentini, S. Ferrero, A. Zambon, S. Tabano, L. Fugazzola, Impact of mutation density and heterogeneity on papillary thyroid cancer clinical features and remission probability. Thyroid 29, 237-251 (2019)

52. A.C. Insilla, A. Proietti, N. Borrelli, E. Macerola, C. Niccoli, P. Vitti, P. Miccoli, F. Basolo, TERT promoter mutations and their correlation with $B R A F$ and $R A S$ mutations in a consecutive cohort of 145 thyroid cancer cases. Oncol. Lett. 15, 2763-2770 (2018)

53. J. Liang, W. Cai, D. Feng, H. Teng, F. Mao, Y. Jiang, S. Hu, X. Li, Y. Zhang, B. Liu, Z.S. Sun, Genetic landscape of papillary thyroid carcinoma in the Chinese population. J. Pathol. 244, 215-266 (2018)

54. H. Ren, Y. Shen, D. Hu, W. He, J. Zhou, Y. Cao, Y. Mao, Y. Dou, W. Xiong, Q. Xiao, Y. Zhang, X. Su, Co-existence of BRAFV600E and TERT promoter mutations in papillary thyroid carcinoma is associated with tumor aggressiveness, but not with lymph node metastasis. Cancer Manag. Res. 10, 1005-1013 (2018)

55. D. Rusinek, A. Pfeifer, J. Krajewska, M. Oczko-Wojciechowska, D. Handkiewicz-Junak, A. Pawlaczek, J. Zebracka-Gala, M. Kowalska, R. Cyplinska, E. Zembala-Nozynska, M. Chekan, E. Chmielik, A. Kropinska, R. Lamch, B. Jurecka-Lubieniecka, B. Jarzab, A. Czarniecka, Coexistence of TERT promoter mutations and the BRAF V600E alteration and its impact on histopathological features of papillary thyroid carcinoma in a selected series of Polish patients. Int J. Mol. Sci. 19, pii: E2647 (2018)

56. S. Watutantrige-Fernando, F. Vianello, S. Barollo, L. Bertazza, F. Galuppini, E. Cavedon, S. Censi, C. Benna, E.C. Ide, A. Parisi, D. Nacamulli, M. Iacobone, G. Pennelli, C. Mian, The Hobnail variant of Papillary Thyroid Carcinoma: clinical/molecular characteristics of a large monocentric series and comparison with conventional histotypes. Thyroid 28, 96-103 (2018)

57. A.M. Poma, R. Giannini, P. Piaggi, C. Ugolini, G. Materazzi, P. Miccoli, P. Vitti, F. Basolo, A six-gene panel to label follicular adenoma, low- and high-risk follicular thyroid carcinoma. Endocr. Connect. 7, 124-132 (2018)

58. K.S. Wong, S.E. Higgins, E. Marqusee, M.A. Nehs, T. Angell, J. A. Barletta, Tall cell variant of papillary thyroid carcinoma: impact of change in WHO definition and molecular analysis. Endocr. Pathol. 30, 43-48 (2019)

59. A. Crescenzi, P. Trimboli, D.C. Modica, C. Taffon, L. Guidobaldi, S. Taccogna, A. Rainer, M. Trombetta, E. Papini, G. Zelano, Preoperative assessment of TERT promoter mutation on thyroid core needle biopsies supports diagnosis of malignancy and addresses surgical strategy. Horm. Metab. Res. 48, 157-162 (2016)

60. I.J. Marques, M.M.Moura, R.Cabrera, A.E.Pinto, J.Simões-Pereira, C.Santos, F.D.Menezes, D.Montezuma, R.Henrique, M.R. Teixeira, V.Leite, B.M.Cavaco, Identification of somatic TERT promoter mutations in familial nonmedullary thyroid carcinomas. Clin. Endocrinol. 87, 394-399 (2017).

61. J. Lee, S. Jeong, C.R. Lee, C.R. Ku, S.W. Kang, J.J. Jeong, K.H. Nam, D.Y. Shin, W.Y. Chung, E.J. Lee, Y.S. Jo, GLI1 transcription factor affects tumor aggressiveness in patients with papillary thyroid cancers. Medicine 94, e998 (2015)

62. C. Tavares, M.J. Coelho, C. Eloy, M. Melo, A.G. da Rocha, A. Pestana, R. Batista, L.B. Ferreira, E. Rios, S. Selmi-Ruby, B. Cavadas, L. Pereira, M. Sobrinho Simões, P. Soares, NIS expression in thyroid tumors, relation with prognosis clinicopathological and molecular features. Endocr. Connect. 7, 78-90 (2018)

63. G. Gandolfi, M. Ragazzi, D. de Biase, M. Visani, E. Zanetti, F. Torricelli, V. Sancisi, M. Gugnoni, G. Manzotti, L. Braglia, S. Cavuto, D.F. Merlo, G. Tallini, A. Frasoldati, S. Piana, A. Ciarrocchi, Genome-wide profiling identifies the THYT1 signature as a distinctive feature of widely metastatic Papillary Thyroid Carcinomas. Oncotarget 9, 1813-1825 (2018)

64. M.S. Dettmer, A. Schmitt, H. Steinert, D. Capper, H. Moch, P. Komminoth, A. Perren, Tall cell papillary thyroid carcinoma: new diagnostic criteria and mutations in BRAF and TERT. Endocr. Relat. Cancer 22, 419-429 (2015)

65. T.H. Kim, C.S. Ki, H.S. Kim, K. Kim, J.H. Choe, J.H. Kim, J.S Kim, Y.L. Oh, S.Y. Hahn, J.H. Shin, H.W. Jang, S.W. Kim, J.H. Chung, Refining dynamic risk stratification and prognostic groups for differentiated thyroid cancer with TERT promoter mutations. J. Clin. Endocrinol. Metab. 102, 1757-1764 (2017)

66. L. Morandi, A. Righi, F. Maletta, P. Rucci, F. Pagni, M. Gallo, S. Rossi, L. Caporali, A. Sapino, R.V. Lloyd, S. Asioli, Somatic mutation profiling of hobnail variant of papillary thyroid carcinoma. Endocr. Relat. Cancer 24, 107-117 (2017)

67. J.O. Paulsson, N. Mu, I. Shaobo, N. Wang, J. Zedenius, C. Larsson, C.C. Juhlin, TERT aberrancies-a screening tool for malignancy in follicular thyroid tumours. Endocr. Relat. Cancer 25, 723-733 (2018)

68. R. Liu, J. Bishop, G. Zhu, T. Zhang, P.W. Ladenson, M. Xing, Mortality risk stratification by combining BRAF V600E and TERT promoter mutations in papillary thyroid cancer: genetic duet of $B R A F$ and TERT promoter mutations in thyroid cancer mortality. JAMA Oncol. 3, 202-208 (2017)

69. R. Liu, M. Xing, Diagnostic and prognostic TERT promoter mutations in thyroid fine-needle aspiration biopsy. Endocr. Relat. Cancer 21, 825-830 (2014)

70. M.C. Topf, Z.X. Wang, M. Tuluc, E.A. Pribitkin, TERT, HRAS, and EIF1AX mutations in a patient with follicular adenoma. Thyroid 28, 815-817 (2018)

71. A. Proietti, C. Sartori, E. Macerola, N. Borrelli, G. Materazzi, P. Vitti, F. Basolo, Low frequengcy of TERT promoter mutations in a series of well-differentiated follicular-patterned thyroid neoplasms. Virchows Arch. 471, 769-773 (2017)

72. R.V. Lloyd, R.Y. Osamura, G. Klöppel, J. Rosai (Eds), WHO classification of tumours of endocrine organs WHO/IARC classification of tumours, 4th edn., 10. (France: International agency for Research on Cancer (IARC), 2017) 